\title{
Cochlear Implants in Patients with Fluctuant or Progressive Hearing Loss on the Better Ear
}

\author{
Pedro Luiz Mangabeira-Albernaz ${ }^{1}$ Andrea Felice dos Santos Malerbi ${ }^{2}{ }^{\circledR}$ \\ ${ }^{1}$ Hospital Israelita Albert Einstein, São Paulo, SP, Brazil \\ ${ }^{2}$ Department of Otolaryngology, Universidade de São Paulo, São \\ Paulo, SP, Brazil

\begin{abstract}
Address for correspondence Pedro Luiz Mangabeira-Albernaz, MD, PhD, Hospital Israelita Albert Einstein, São Paulo, SP, Brazil (e-mail: albernaz@einstein.br).
\end{abstract}

Int Arch Otorhinolaryngol 2021;25(1):e129-e134.

Abstract
Keywords
- unilateral hearing loss
- sensorineural hearing
$\quad$ loss
- cochlear implants

Introduction Cochlear implants have been proposed for cases of unilateral hearing loss, especially in patients with tinnitus impairment. Several studies have shown that they result in definite improvement of sound localization and speech understanding, both in quiet and noisy environments. On the other hand, there are few references regarding cochlear implants in patients whose better ears present hearing loss.

Objective To report the audiological outcomes of three patients with unilateral deafness, in whom the better ears presented hearing losses, submitted to cochlear implants.

Methods Three patients with unilateral profound hearing loss underwent a cochlear implant performed by the same surgeon.

Results The patients' data are presented in detail.

Conclusion The indications for cochlear implants are becoming more diverse with the expansion of clinical experience and the observation that they definitely help patients with special hearing problems.

\section{Introduction}

Cochlear implants have been available since $1957^{1}$ and are now the treatment of choice for patients with profound hearing loss and/or very poor speech discrimination.

They have also been proposed for cases of unilateral hearing loss, and several studies have shown that they result in definite improvement in sound localization and speech understanding, both in quiet and noisy environments. They have also been helpful for patients with intense tinnitus. Many investigators feel that cochlear implants are superior to other devices, such as devices for contralateral routing of sound (CROS) and osseointegrated implants, for stimulating the deaf ear rather than send sounds to the opposite ear, but there are still some controversies in relation to these

received

August 22, 2019

accepted

December 21, 2019

published online

May 13, 2020 opinions. ${ }^{2-7}$ According to Dillon et al, ${ }^{8}$ cochlear implantation in cases of substantial hearing loss may offer significant improvements in the quality of life; quality of life measures revealed a reduction in perceived tinnitus severity and subjective improvements in speech perception in noise, spatial hearing, and listening effort.

On the other hand, there are few references regarding cochlear implants in patients whose better ears also present some degree of hearing loss. ${ }^{9,10}$ This situation can be quite complex, particularly when the hearing in the better ear is apt to progressively deteriorate. The same sort of consideration applies to patients with fluctuant hearing losses in their better ears, as during the episodes of more intense hearing loss, they experiment difficult social and professional situations. (c) 2020. Fundação Otorrinolaringologia. All rights reserved.

This is an open access article published by Thieme under the terms of the Creative Commons Attribution-NonDerivative-NonCommercial-License, permitting copying and reproduction so long as the original work is given appropriate credit. Contents may not be used for commercial purposes, or adapted, remixed, transformed or built upon. (https://creativecommons.org/ licenses/by-nc-nd/4.0/)

Thieme Revinter Publicações Ltda., Rua do Matoso 170, Rio de Janeiro, RJ, CEP 20270-135, Brazil 
A European consensus defined asymmetrical hearing loss as an elevation, in the poorer ear, of 30 to $60 \mathrm{~dB}$ in the averaged thresholds of $0.5 ; 1 ; 2$; and $4 \mathrm{KHz}$ in relation to the better ear. For those patients, a cochlear implant can be fitted in the ear with severe-to-profound hearing loss as a solution for restoring binaural hearing.

The present report refers to three patients with unilateral deafness in whom the better ears presented hearing loss. Two of them presented fluctuant hearing loss.

\section{Methods}

A unilateral cochlear implant was performed by the same surgeon in three patients with asymmetrical hearing loss, first seen in a private clinic.

The placement of the electrodes was accomplished through the facial recess; a cochleostomy was performed in each case.

This study was approved by the Ethic Counsel of the Albert Einstein Hospital in Sao Paulo (CAAE 17456219.2.0000.0071).

- Table 1 presents the age of the patient at the onset of the disorder, age at implantation, and etiology of the hearing loss.

\section{Results}

\section{Case 1}

Patient 1, male, 48 years old when first seen in consultation on Feb $21^{\text {st }}, 2000$, with a complaint of intense tinnitus in the right ear. In 1991, he had an episode of bilateral sudden deafness, accompanied by intense vertigo that lasted for 2 weeks. After approximately 3 weeks, he felt an improvement in the hearing of the left ear.

His ear, nose and throat examination was essentially normal. The audiological examination showed profound sensorineural hearing loss in the right ear and a high tone loss in the left ear. The vestibular examination showed hypoactive responses in the right ear.

The etiology of the hearing losses could not be established. The tests for autoimmune diseases were negative. The hypothesis of atypical Menière disease was taken in consideration, but, except for the first vertiginous episodes, the sensation of vertigo lasted only for a few minutes.

He returned on Sep $21^{\text {st }}, 2005$, with a complaint of fluctuant hearing loss in the left ear and attacks of vertigo. The tinnitus persisted, and he had episodes of depression, usually during the periods of more intense hearing loss in his hearing ear. He was then advised to have a cochlear implant in the right ear. His health insurance company did not

Table 1 Characteristics of the implanted patients

\begin{tabular}{|l|l|l|l|}
\hline Patient & Age at Onset & Age at Implant & Etiology \\
\hline Case 1 & 39 & 54 & unknown \\
\hline Case 2 & 33 & 48 & otosclerosis \\
\hline Case 3 & 8 & 36 & $\begin{array}{l}\text { Mondini } \\
\text { dysplasia }\end{array}$ \\
\hline
\end{tabular}

approve the implant, based on the fact that he did not have profound hearing loss in both ears.

Only in September 2006 did he obtain the approval for the implant. His depression was then very intense, and his wife had left him.

On Sep $21^{\text {st }}, 2006$, he was submitted to a cochlear implant in the right ear. An Advanced Bionics HiRes 90K Hi-Focus (Advanced Bionics Corp., Valencia, CA, USA) unit was used. The activation of the external unit was performed on Nov $24^{\text {th }}, 2006$, with all electrodes functional. Two of them were permanently activated to reduce the patient's tinnitus, and this strategy was quite effective.

The quality of life of the patient was definitively improved by the cochlear implant. A detailed analysis of the quality of life was not performed.

The patient still has fluctuations in his left ear, but the thresholds did not show marked changes.

-Fig. 1 shows the audiogram of this patient that remained unaltered, except during the episodic fluctuations.

\section{Case 2}

Patient 2, female, 43 years old. Her first consultation was on Jan $19^{\text {th }}, 2006$. She related that she had otosclerosis and that the disease became evident when she was pregnant with her first son. In the past 10 years, she wore bilateral hearing aids, but in the last months she could not hear from the right ear. She also referred that 2 weeks before this consultation, she had an episode of intense tinnitus and discomfort in the left ear. These symptoms disappeared after she was medicated with prednisolone. Laboratory tests for autoimmune disease were found to be negative.

The ear, nose and throat examination was normal. The audiogram showed mixed hearing loss, with small air-bone gaps (-Fig. 2).

The patient was advised to have a stapedectomy in the right ear. The procedure was performed on Jan $24^{\text {th }}, 2006$.

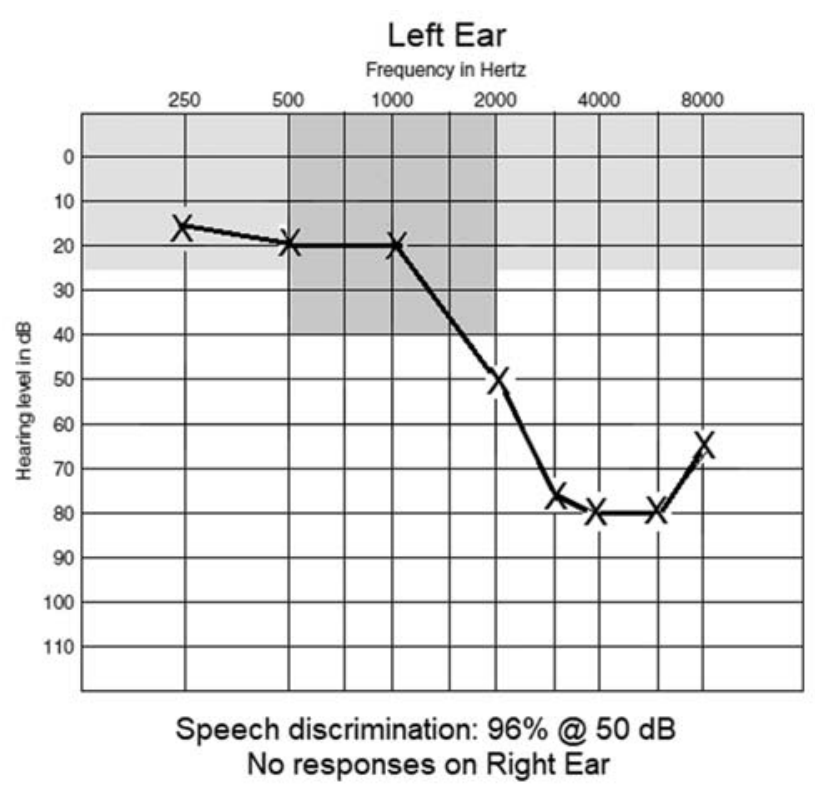

Fig. 1 Audiogram of patient 1. 


\section{Right Ear}

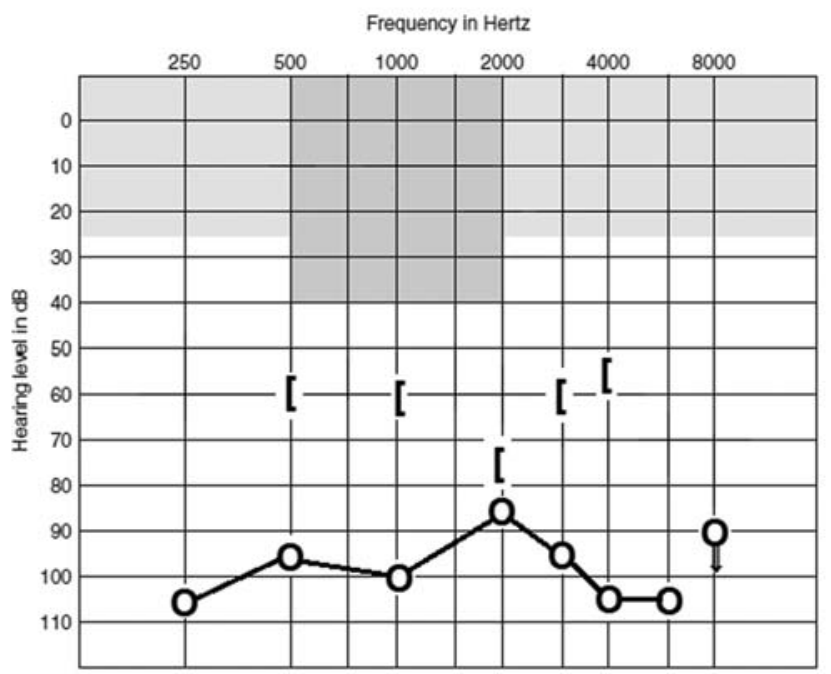

Speech discrimination: 60\% @ $100 \mathrm{~dB}$

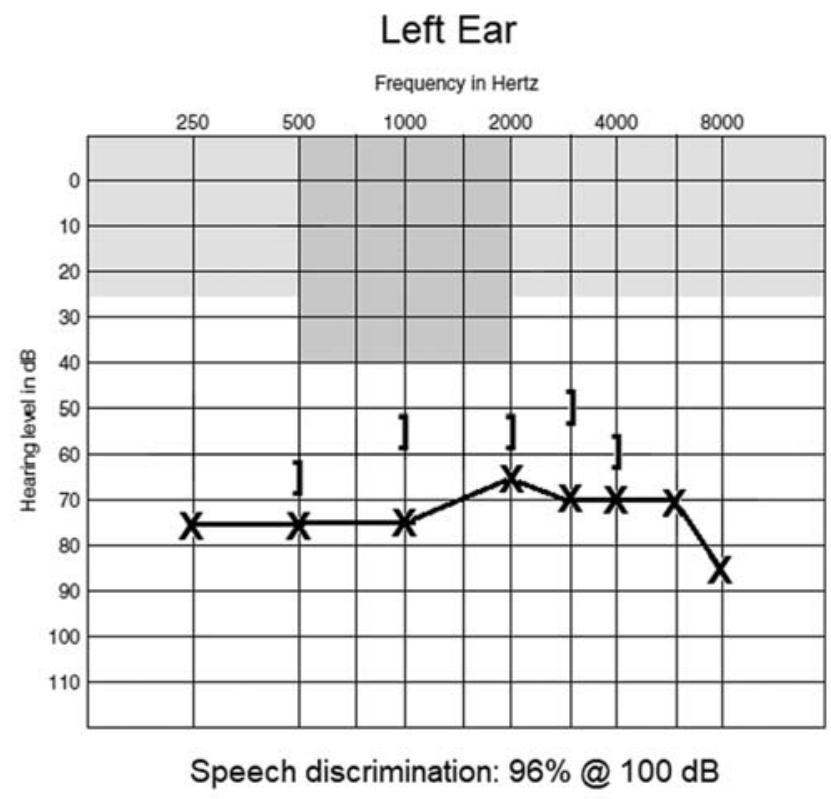

The computed tomography (CT) scans (-Fig. 3) showed intense demineralization in both cochleae.

-Fig. 4 shows a computer reconstruction of the left inner ear.

The cochlear implant operation was performed on Dec $16^{\text {th }}, 2011$. A Nucleus Freedom (Cochlear Ltd., Sydney, Australia) unit was used. The activation was performed on Jan $16^{\text {th }}, 2012$, and all electrodes were functioning.

The patient's last available audiogram was performed on May $6^{\text {th }}, 2015$. She is now hearing well with the implant and uses it to speak on the telephone. The right ear did not change and she still wears a hearing aid in this ear (-Fig.5). She has a definitely better quality of life after the implant.

\section{Case 3}

Patient 3, female, 8 years old. She came to consultation on Oct $7^{\text {th }}, 1985$, with a history of difficulties in school. Her ear, nose and throat examination was essentially normal, and the audiogram showed moderate hearing loss in the right ear

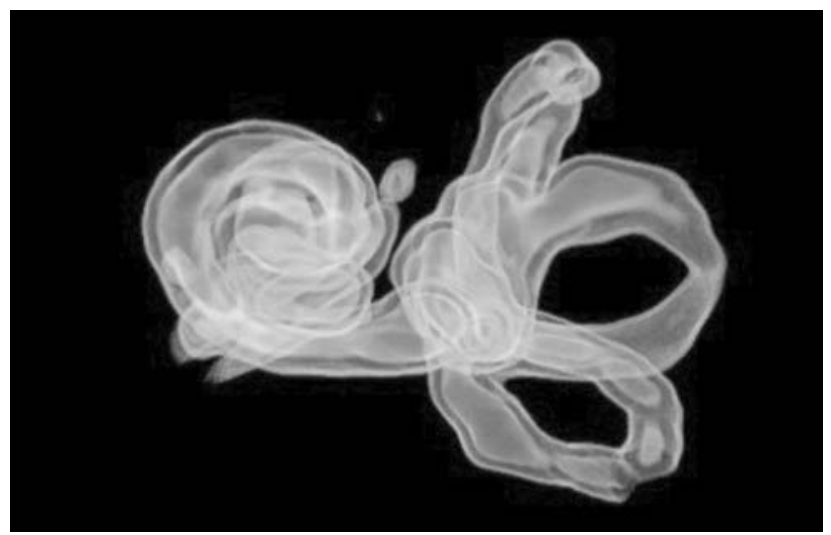

Fig. 4 Computer reconstruction of patient 2 left ear.

Fig. 3 Preimplant computed tomography scans of Patient 2. 


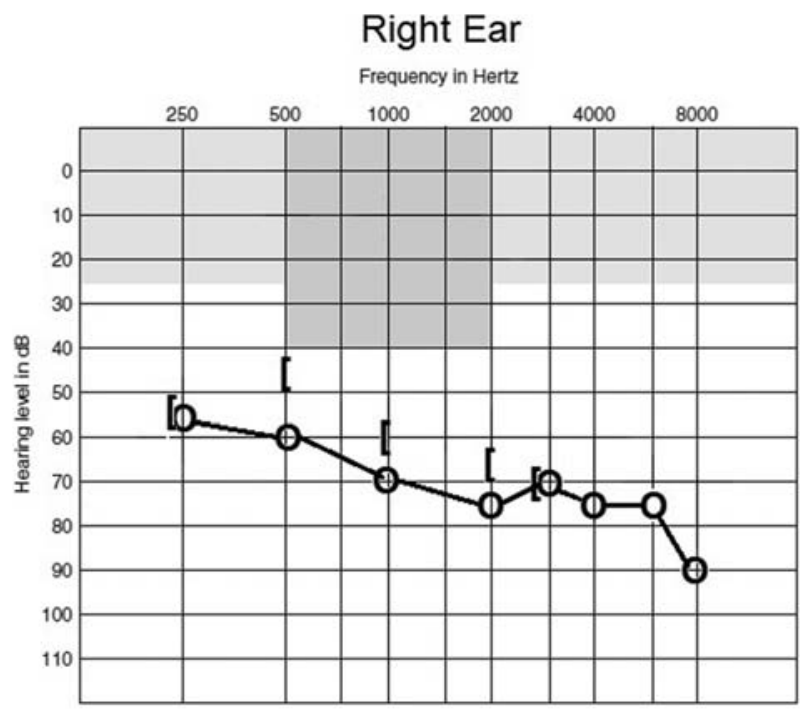

Speech discrimination: 96\% @ $90 \mathrm{~dB}$ No responses on Left (implanted) ear

Fig. 5 Audiogram of patient 2 on 06-May-2015.

and profound hearing loss in the left ear. The temporal bone hypocycloidal polytomography showed bilateral Mondini dysplasia.

On Jan $29^{\text {th }}, 1986$, she was submitted to a left-ear endolymphatic-subarachnoid shunt. The hearing loss in this ear ceased to fluctuate but the thresholds remained basically unchanged and socially useless.

She wore a hearing aid in the right ear and her schooling was quite satisfactory in spite of the episodes of fluctuation in this ear, which became worse after 1994. She graduated as a lawyer in 2002 and felt that her hearing, with the help of the hearing aid, was socially and professionally adequate. The

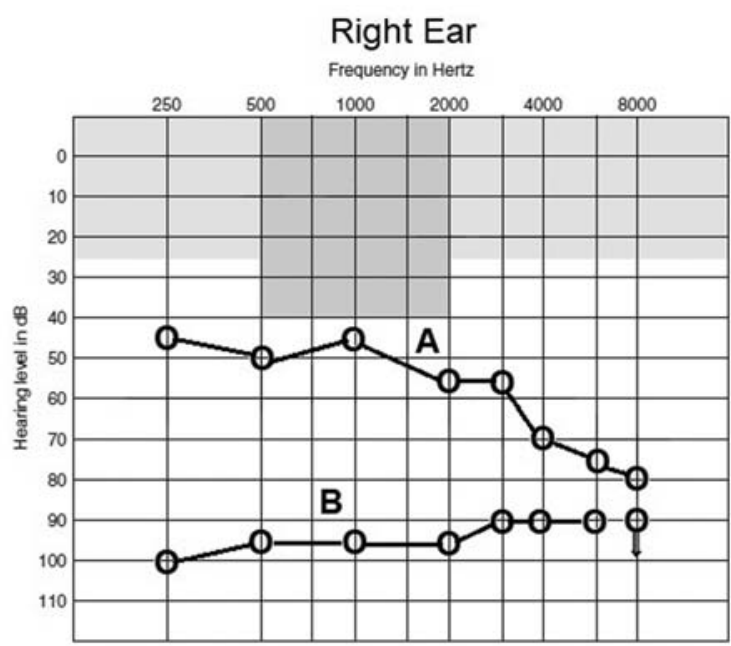

Audio A - 01-Jul-2002 - Speech discrimination: 80\% @ 90 dB

Audio B - 12-May-2017 - Speech discrimination: 0\% @ 100 dB

Fig. 6 Audiograms of patient 3.

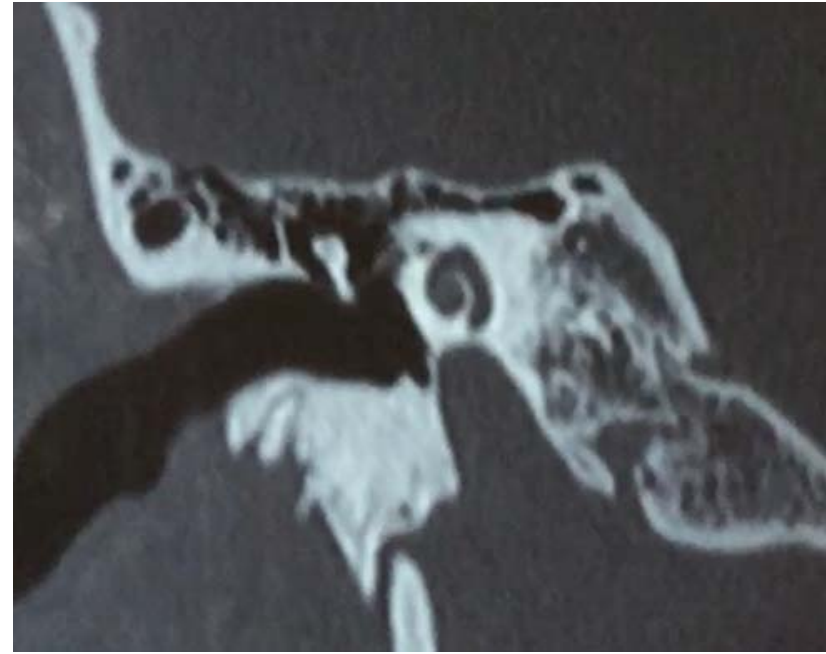

Fig. 7 Computed tomography scan of patient 3's right temporal bone.

audiogram performed on Jul $1^{\text {st }}, 2002$ is seen in - Fig. 4 (curve A).

Gradually, the episodes of fluctuation, although infrequent, became more intense. In 2011, she was advised to have a cochlear implant in the left ear. - Fig. 6 shows the audiograms for patient 3 .

-Figs. 7 and 8 show the patient's preoperative CT scans for the right and left ears.

-Fig. 9 shows a computer reconstruction of the inner ears.

A Nucleus Freedom system was implanted in her left ear on May $8^{\text {th }}, 2013$, and was activated on Jun $18^{\text {th }}, 2013$.

In December 2016, she had a sudden hearing loss in her right ear. The audiograms performed on Jan $23^{\text {rd }}, 2017$, and May $12^{\text {th }}, 2017$, show that her hearing thresholds were higher and her speech discrimination was $0 \%$ ( - Fig. 4, curve B). After a few months, she had partial recovery of her right ear, which allowed her to wear a hearing aid again.

She knows that she may have further episodes of intense fluctuation in her right ear, and the implant is her most reliable means for social and professional communication. The knowledge that she may always maintain

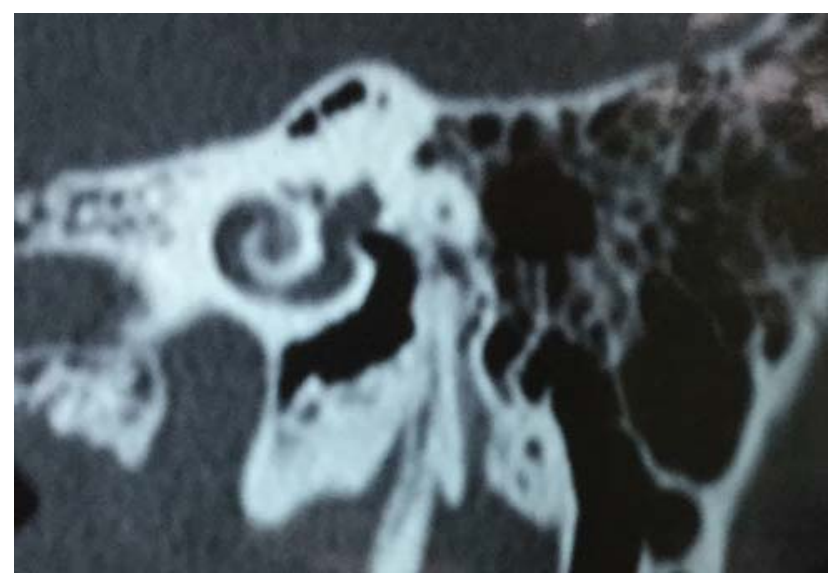

Fig. 8 Computed tomography scan of patient 3's left temporal bone. 


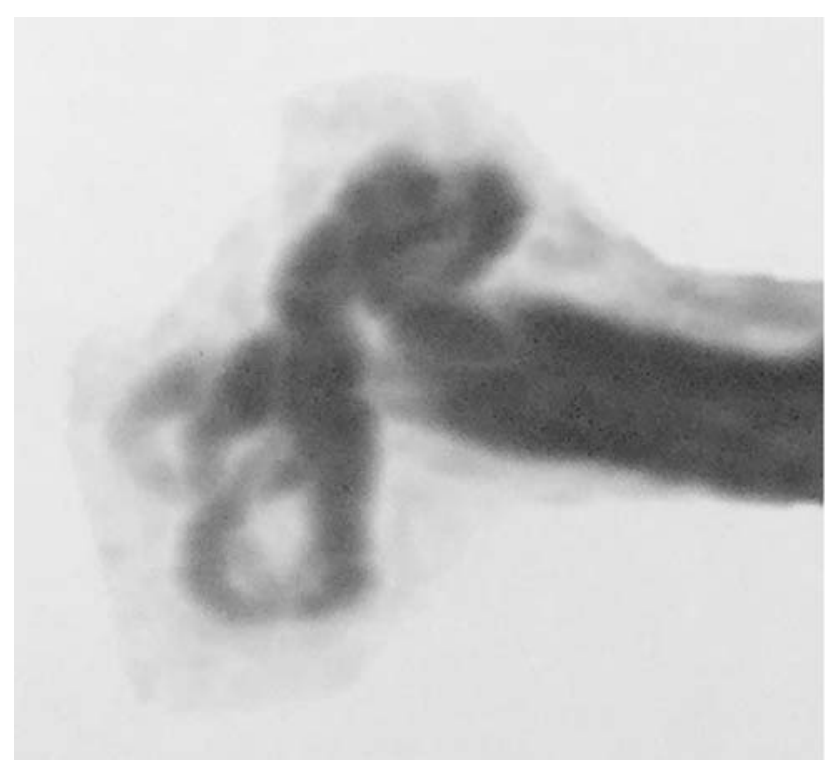

Fig. 9 Computer reconstruction of patient 3's inner ears.

good hearing in the implanted ear definitely improved her quality of life.

\section{Discussion}

These clinical cases are examples of a situation in which one of the ears presents a profound hearing loss and the better ear has a significant probability of evolving to a similar condition. These patients still have useful hearing in their better ears. Two of them, however, continue to present episodes of fluctuation.

Fluctuant hearing loss is a difficult problem. Dispensing a hearing aid is quite complicated, as it often needs readjustments, not only in relation to thresholds, but also to the degrees of compression needed to reduce recruitment. In patients that have episodes of fluctuation in their only useful ear, it often means social and professional problems during the episodes in which the hearing is worse.

The hearing in patients with Mondini dysplasia is quite variable. There are cases with normal hearing throughout their lives, whereas in others the structural defects led to profound bilateral loss. ${ }^{11,12}$ Patient 3 had useful hearing up to 40 years of age in the better ear but is now dependent on the cochlear implant for her social and professional life.

One common characteristic of these patients is that the ability to use the implant was acquired more slowly than that usually observed in postlingual implant cases. It is feasible to admit that the central nervous system has more difficulties in learning to interpret the electrical information provided by the implant while the strategy for interpreting sounds with the better ear can still be used. Patient 1 was quite happy with his implant soon after the activation, but this happened mainly because of the significant reduction of his incapacitating tinnitus. The other two patients took more than a year to derive adequate benefit from their cochlear implants.

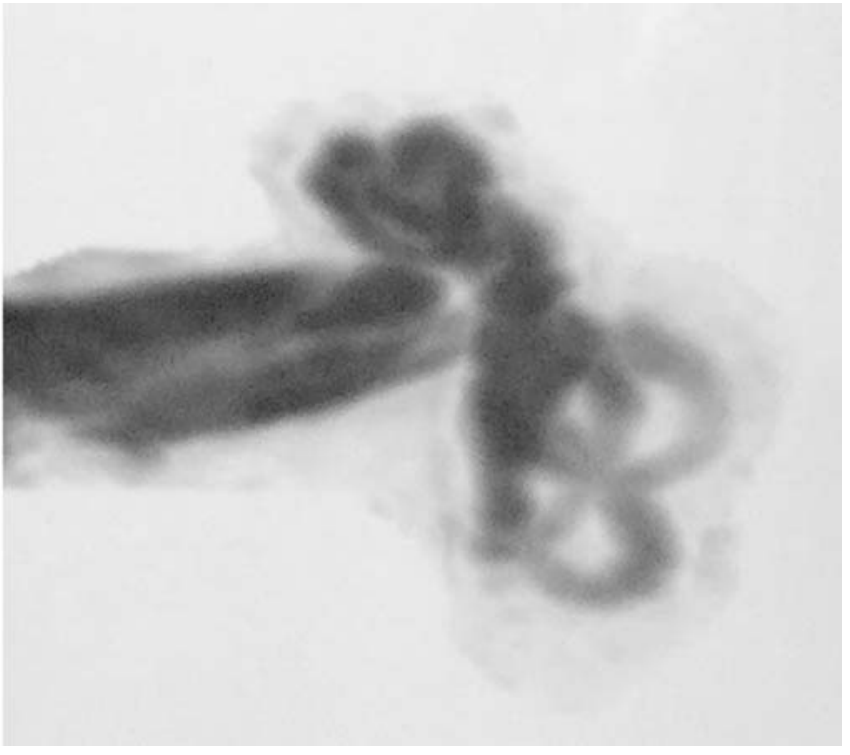

It is quite possible that the more difficult adaptation of the cochlear implant in hearing patients should be taken into consideration when indicating implants for patients with unilateral deafness and normal better ears. This circumstance, however, does not constitute a contraindication to cochlear implants in these patients.

As stated by Russo et al, ${ }^{10}$ "when incapacitating fluctuating hearing loss occurs in patients presenting a contralateral deaf ear, a cochlear implant is indicated in the latter ear, significantly improving performance in noisy conditions and allowing a better quality of communication to be achieved."

\section{Conclusion}

The initial concept that cochlear implants would be indicated only for patients with profound bilateral hearing loss has changed considerably in recent ears. New indications were added to the old ones, including patients with unilateral hearing loss. Patients with progressive or fluctuant hearing loss in their better hearing ears must be included in these indications. There is no question that the indications for cochlear implant are becoming more diverse with the expansion of clinical experience and that they may help many patients with special hearing problems.

Note

This study was approved by the Ethic Counsel of Hospital Israelita Albert Einstein (CAAE 17456219.2.0000.0071).

Conflict of Interests

The authors have no conflict of interests to declare.

\section{References}

1 House WF, Berliner K, Crary W, et al. Cochlear implants. Ann Otol Rhinol Laryngol 1976;85(3Pt2):(Suppl 27):1-93 
2 Tokita J, Dunn C, Hansen MR. Cochlear implantation and singlesided deafness. Curr Opin Otolaryngol Head Neck Surg 2014;22 (05):353-358. Doi: 10.1097/MOO.0000000000000080

3 Cabral Junior F, Pinna MH, Alves RD, Malerbi AFS, Bento RF. Cochlear Implantation and Single-sided Deafness: A Systematic Review of the Literature. Int Arch Otorhinolaryngol 2016;20(01): 69-75. Doi: 10.1055/s-0035-1559586

4 Lorens A, Kruszyńska M, Obrycka A, Skarzynski PH, Wilson B, Skarzynski $\mathrm{H}$. Binaural advantages in using a cochlear implant for adults with profound unilateral hearing loss. Acta Otolaryngol 2019;139(02):153-161. Doi: 10.1080/00016489.2018.1535190

5 Galvin JJ III, Fu QJ, Wilkinson EP, et al. Benefits of Cochlear Implantation for Single-Sided Deafness: Data From the House Clinic-University of Southern California-University of California, Los Angeles Clinical Trial. Ear Hear 2019;40(04):766-781. Doi: 10.1097/AUD.0000000000000671

6 Ramos Macías A, Falcón-González JC, Manrique Rodríguez M, et al. One-Year Results for Patients with Unilateral Hearing Loss and Accompanying Severe Tinnitus and Hyperacusis Treated with a Cochlear Implant. Audiol Neurotol 2018;23(01):8-19. Doi: $10.1159 / 000488755$
7 Buss E, Dillon MT, Rooth MA, et al. Effects of Cochlear Implantation on Binaural Hearing in Adults With Unilateral Hearing Loss. Trends Hear 2018;22:2331216518771173. Doi: 10.1177/2331216518771173

8 Dillon MT, Buss E, Rooth MA, et al. Effect of Cochlear Implantation on Quality of Life in Adults with Unilateral Hearing Loss. Audiol Neurotol 2017;22(4-5):259-271. Doi: 10.1159/000484079

9 Berrettini S, De Vito A, Bruschini L, Fortunato S, Forli F. Idiopathic sensorineural hearing loss in the only hearing ear. Acta Otorhinolaryngol Ital 2016;36(02):119-126. Doi: 10.14639/0392-100X587

10 Russo FY, De Seta D, Lahlou G, et al. Fluctuating Hearing Loss in the Only Hearing Ear: Cochlear Implantation in the Contralateral Deaf Side. Otolaryngol Head Neck Surg 2018;158(06):1101-1106. Doi: $10.1177 / 0194599818763137$

11 Mangabeira-Albernaz PL, Fukuka Y, Chammas F, Ganança MM The Mondini dysplasia - a clinical study. ORL J Otorhinolaryngol Relat Spec 1981;43(03):131-152

12 Mangabeira-Albernaz PL. The Mondini dysplasia-from early diagnosis to cochlear implant. Acta Otolaryngol 1983;95(56):627-631 